\title{
UM MUNDO VIBRANTE DE FORMAS E CORES NO VIDEOCLIPE DE MICHEL GONDRY
}

\author{
A vibrant world of forms and colours in a Michel G ondry's videodip
}

\begin{abstract}
Lílian Reichert Coelho
Jornalista graduada pela Universidade Estadual de Londrina, Professora do curso de Comunicação Social-Jornalismo da Faculdade Social da Bahia, D outoranda pelaUniversidadeFederal da Bahia. Salvador, BA - Brasil, e-mail: lilireichert@ gmail.com
\end{abstract}

\section{Resumo}

Uma leitura semiótica do videoclipe F ell in love with a girl é o que apresentamos neste texto. Procuramos oferecer uma mirada analítico-interpretativa da obra, observando as relações intersemióticas instauradas pela composição verbo-músico-visual de Michel G ondry para a canção da banda de rock norte-americana TheW hite Stripes. N osso objetivo principal é, a partir da observação dos arranjos sintáticos, identificar o modo como o referido videoclipe constrói sentido na contemporaneidade. Para tanto, empregamos as noções de propriedade icônica e propriedade plástica oferecidas pela retórica visual do Groupem, um coletivo de autores cuja contribuição consideramos profícua para a análise de produtos comunicacionais massivos. Complementamos tal apropriação das referidas noções, propondo operadores de análise que julgamos eficientes na análise do videoclipe.

Palavras-chave: Videoclipe; Semiótica; Visual.

\begin{abstract}
A semiotic reading of the videoclip Fell in love with a girl is what we present in this text. We intend to offer an analytical-interpretative perspective of the video, in an attempt to observe the intersemiotical relations proposed by Michel Gondry in the composition - wich is verbal, musical and visual -for the song of the north-american rock band The White Stripes. Our main goal is to identify - by the observation of the internal arrangements - the way this videoclip builds up sense in the contemporary world. To do so, we use the notions of iconical and esthetical properties offered by the Visual Rethoric studies developed by Groupem, a group of authors whose contribution we consider efficient to the mass communicational product's analysis. We complement the above mentioned concepts proposing our own analytical scheme, wich we believe can be efficient to videoclip's analysis.
\end{abstract}

Keywords: Videoclip; Semiotics; Visual. 


\section{INTRODUÇÃO}

A leitura do videoclipe $F$ ell in love with a girl que apresentamos neste texto fundamenta-se na defesa da ideia de que a estrutura visual dos videoclipes tem lógica própria, associadaao contexto da música pop constituída, de acordo com G oodwin (1992, p. 86), por três códigos: música, canção e iconografia. Guia a análise proposta a articulação entre as dimensões visual e musical do videoclipe selecionado. 0 videoclipe constitui um dos fenômenos mais expressivos da cultura midiática contemporânea e pode ser compreendido tanto como a representação visual da música pop, tal como concebe Goodwin (1992), ou conforme Wollen (1986) apud FISKE (1987, p. 254), que 0 define como "uma mistura especial de propaganda e programa, o visual funcionando como propaganda se se considerar a canção uma amostra da mercadoria." ${ }^{1}$ Outra definição pertinente pode ser encontrada em Shuker (1999, p. 289):

Forma cultural híbrida, reunindo elementos da televisão e do rádio. [...] 0 videoclipe segue as convenções do single tradicional de 45 rpm. Possui uma duração de dois a três minutos, funcionando - nos próprios termos da indústria - como uma 'peça promocional' que estimula a venda do disco e influencia a parada de sucessos.

As definições acima não se contradizem, mas apresentam matizes diferentes, convergindo no que concerne ao caráter publicitário do videoclipe, o que não impede - até confirma - a exigência de que o produto seja analisado em suas propriedades formais pois, mesmo destinado à promoção de outro(s) produto(s), constitui-se algo singular. Ao estabelecer como questão central a busca por um modo satisfatório para a análise de videoclipes no que tange às propriedades formais do produto, propomos uma abordagem sobre 0 valor operacional de duas noções caras à retórica visual desenvolvida pelo Grupem, quais sejam: as de signo icônico e signo plástico. Por opção teóricometodológica, preferimos abordá-las não como classes de signos presentes nos textos visuais, mas como manobras discursivas, determinantes do sentido no produto midiático em questão no que concerne às relações entre as dimensões visual e sonora, esta última considerada em seus dois aspectos constitutivos: música e letra da canção.

Saliente-se que não pretendemos sugerir uma análise fundamentada na compreensão discretizante signo a signo ou em relações entre elementosisolados, pois concebemos os videoclipes como unidades de sentido em seu aspecto geral, não isolável em partes autônomas, o que nos permite abandonar a análise pontual, em favor da busca pelas estratégias, pelos recursos composicionais presentes no videoclipe. Nosso percurso concentrase, portanto, na organização sintagmática do produto. Por opção metodológica, não tratamos de signos icônicos e signos plásticos, mas de propriedade icônica e propriedade plástica. A presentamos, abaixo, uma breve observação sobre o termo iônico.

Por remeter incondicionalmente aos debates teóricos sobre iconicidade, que não fazem parte da presente investigação, optamos pelo uso do termo figurativo, em contraste com o plástico, o primeiro convidando inevitavelmente à leitura de uma narrativa visual, enquanto o segundo refere-se mais enfaticamente às propriedades expressivas dos elementos visuais como cores, formas e texturas. A relevância do plástico na análise da retórica da imagem é enfatizada pelo Grupem (1992, p. 239), ao constatar que "os autores que trabalharam com a 'retórica da imagem' só consideraram a retórica do signo icônico." Evidente, na passagem citada, a referência que o coletivo faz ao trabalho de Roland Barthes (1982), principalmente aos textos A retórica da imagem e A mensagem fotográfica.

Quanto às propriedades plásticas, podese afirmar que desempenham função distintiva, por não possuírem valores fixos propiciando, a partir do seu emprego, que as propriedades figurativas sejam transformadas em relação ao consenso cultural, a qualquer norma estabilizada culturalmente. Os desvios causados por tais transformações constituem operações retóricas responsáveis pelo esgarçamento de sentidos possíveis (polissemia), criando leis internas a cada videoclipe pois, como aponta o Grupem, (1992, p. 251), "as normas e as regularidades que estruturam o mundo plástico são imanentes ao enunciado e não podem projetar suas determinações fora deste."

\footnotetext{
No original: WO LLHEIM, R. A arte e seus objetos. São Paulo: Martins Fontes, 1993. "points out music video is a special mix of ad and program, for the visuals act as na ad whereas the sound track is a sample of the commodity".
} 
Julgamos que a classificação das propriedades figurativa e plástica tem valor metodológico claro embora, no confronto com 0 fenômeno, a fronteira entre elas nem sempre seja nítida, como é possível observar no clipe F ell in love with a girl, em que se pode reconhecer figuras humanas construídas como peças delego animadas e coloridas, tornando ambíguaa leitura, chamando atenção muito mais para a alteração das formas e cores do que para as figuras e as ações que desempenham. $\mathrm{Na}$ perspectiva do Grupem, (1992, p. 252), os signos icônicos não podem manifestar-se materialmente de maneira autônoma dentro de um enunciado, pois só podem ser atualizados pelos signos plásticos "e esta coexistência tende a seguir uma lei que chamamos de concomitância." Esta constitui uma das características mais evidentes dos textos televisivos que, excetuando-se o videoclipe e a publicidade, não permite com frequência distanciamentos da figuratividade em proveito das construções privilegiadamente plásticas, pois 0 mundo que constroem guarda, pelo menos na ordem figurativa, referências explícitas com o que se reconhece como o mundo "real" ou não-ficcional. Podemos observar, entretanto, que só existe concomitância na opção figurativa que, para ser levada a cabo, exige um revestimento plástico, ao passo que a opção plástica não necessita da figuratividade, prescindindo, portanto, da lei da concomitância.

A propriedade figurativa tal como se apresenta nos videoclipes é sustentada por um valor pictórico bastante evidente, pelo menos se considerarmoso termo naacepção do G rupem, (1992, p. 183), isto é, como aquilo que se refere a uma imagem em duas dimensões captada visualmente, 0 que nos obriga a levantar a questão do plano-suporte - a tela - cuja bidimensionalidade remete inevitavelmente à pictorialidade G rupem, (1992, p. 187). No que concerne à dimensão figurativa dos videoclipes, oferecemos como categorias de análise:

- presença de narrativa ou de narratividade ${ }^{2}$ (construção problemática do tempo e do espaço, pois as canções da música pop em geral não seguem a estrutura das narrativas clássicas, com começo, meio e fim, e os videoclipes seguem a mesma lógica);

- construção de personagens (diferentemente recebidos se os papéis forem interpretados pelo(s) artista(s) ou por atores profissionais ou modelos;

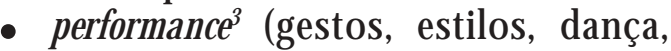
ou seja, modos de aparecer para 0 apreciador).

Em relação à dimensão plástica, sugerimos como categorias:

- ritmo (cortes, movimentos de câmera, interação música-imagem);

- jogos cromáticos e morfológicos;

- elaboração digital;

- apropriação ou citação de estilos fotográficos, cinematográficos, televisivos ou artísticos.

A exposição de nossos operadores de análise conclui-se com uma última afirmação no que tange à dimensão visual dos videoclipes: as relações entre propriedades figurativas e plásticas constituem uma questão de grau, de dominância, muito mais explícita do que em outros produtos da cultura midiática contemporânea. Temos noção de que tais relações encarnam apenas parte de uma das dimensões do videoclipe, subordinada à dimensão musical. Concebemos estaúltima como dominante, tanto no sentido semântico (observe-se a subordinação a elementos já cristalizados pela cultura musical pop e todos os produtos que ela engendra), quanto no sintático, respeitando certas convenções formais. Isso contraria afirmações de pesquisadores que para nós, precipitadamente - insistem em afirmar a total liberdade de composição nos videoclipes. Em nosso ponto de vista, o video clipe apresenta regras de gênero com variações estilísticas tal como qualquer outro fenômeno cultural, conforme pretendemos demonstrar com a leitura do vídeo de Fell in love with a girl, doravante apresentada.

\footnotetext{
2 Narratividade é compreendida, no contexto deste trabalho, naacepção de FABBRI, P. E l giro semiótico. Barcelona: G edisa, 2000. concebida como "um ato de configuração do sentido variável de ações e paixões." [tradução nossa]

3 A noção étomada deFISKE, J. T elevision culture. NewY ork: Routledge, 1987. para quem "a performance envolvealtaintensidade de comunicação: ela é que faz o processo comunicativo, do uso da linguagem e do gesto, o foco de atenção.” [tradução nossa]
} 


\section{Aspectos músico-visuais no videoclipe de Gondry ${ }^{4}$}

O diretor Michel Gondry apresenta um arranjo animado de peças coloridas de montar na composição visual (de 2002) para a canção F ell in love with a girl. As peças de brinquedo ganham vida no videoclipe que acompanha a canção homônima do disco W hite Blood Cells, lançado em 2001 pela dupla norte-americana W hite Stripes, de D etroit, composta por Meg e Jack White. Pelo movimento alucinado das peças geométricas, ${ }^{5}$ em sequência frenética de formas e cores, 0 videoclipe narra uma história de amor. A narratividade visual é instaurada por dois procedimentos: ora por incessantes transformações das figuras de aparência humana em elementos geométricos (plásticos), ora pelo fato de elementos abstratos passarem a constituir figuras humanas, seja por fusão, seja por desintegração. Tal articulação de elementos e procedimentos na construção da narratividade visual suscita aprofundamento acerca da remodelagem das figuras na relação com fundos e com a própria morfologia dos elementos. Para tanto, julgamos profícua a aproximação com pensadores cujas contribuições aos estudos sobre visualidade articulam-se à análise de videoclipes.

Ao apontar diversas possibilidades de transformações em fotografias, Savendoff (2000) apresenta uma variedade de relações entre 0 representado e o modo como é percebido na representação, considerando a peculiaridade da experiência oferecida e os recursos manejados. Isso equivale a dizer que 0 argumento fundamentase no pressuposto de que, ao depararmo-nos com uma fotografia, a percebemos como fotografia e não como pintura, por exemplo. Isto equivale a dizer que a materialidade desempenha função primordial naapreciação e, portanto, na construção do sentido. Savendoff explica que:

[...] nós experimentamos fotografias de modo diverso de pinturas e que as exigências críticas das duas divergem. Explico tal divergência não por mostrar que a fotografia é, de fato, mais ligada à realidade do que a pintura, mas mostrando que nós a percebemos desta forma. Justificado ou não, tendemos a ver fotografias como cópias objetivas do mundo etal tendência tem larga influência na interpretação e na avaliação. (SAVEND O FF, 2000, p. 49).

A reflexão proposta por Savendoff (2000, p. 84), resgata o argumento da transparência, de Kendall Walton (1990), que ressalta a supremacia da fotografia sobre a pintura no que concerne ao seu valor documental pelanaturezamecânicadaprimeira, maisligadaao "real". Savendoff, entretanto, reformula o argumento, afirmando que "as fotografias são percebidas como portadoras de uma objetividade não disponível à pintura." Pelo exposto, observa-se que se trata de comparação complicada, uma vez que existem graus de iconicidade e, portanto, possibilidades distintas de criação do efeito de real. Savendoff circunscreve o tipo de objetividade a que fotografiaestáatrelada, problematizando umaquestão cara à reflexão sobre produtos visuais icônicos, a saber, a correspondência "verdadeira":

Na verdade, as fotografias podem estar longe da objetividade no modo como apresentam um assunto; as escolhas do ângulo da câmera pelo fotógrafo, a iluminação, o corte, tudo influencia no modo como o assunto será visto. Além disso, as características do meio - sua bidimensionalidade, a delimitação da imagem, o uso de preto-e-branco - tudo contribui para a divergência entre 0 que vemos na fotografia e 0 que veríamos pessoalmente. Contudo, nossa consciência sobre tais fatores não altera o modo como vemos as fotografias - como algo que tem uma ligação especial com a realidade. (SAVEND OFF, 2000, p. 87).

Ao examinar os tipos de transformação possibilitados pela fotografia, Savendoff (2000, p. 88) salienta que, mesmo ao sabermos que o representado e o modo como estáconfigurado natelanão corresponde

\footnotetext{
4 Michel G ondry nasceu em V ersailles, França, em 1963, e aparece no cenário midiático no final dos anos 80 e início dos 90 , tornando-se reconhecido mundialmente como produtor de peças publicitárias, incluindo video clipes. Sua pro dução destacase, principalmente, após realizar diversos vídeos para a cantora islandesa Björk. O reconhecimento de G ondry advém do tratamento experimental conferido pelo diretor aos videoclipes, ultrapassando alógica comercial inerente ao referido produto comunicacional massivo. A pós a consolidação de sua carreira co mo realizador publicitário, G ondry aventurou-se pelo cinema, dirigindo dois longa-metragens A natureza humana (2001) e Brilho eterno de uma mente sem lembranças (2004). REZEND E, M. C iência do sonho: a imaginação sem fim do diretor Michel G ondry. São Paulo: Alameda, 2005.

5 O vídeo tem duração de 1 minuto e 53 segundos.
} 
pontualmente às coisas do mundo em sua existência "real", tridimensional, não vemos de acordo com 0 conteúdo, mas segundo a maneira como nos é dado a ver. $\mathrm{O}$ argumento éreforçado pelo apelo àspropriedades do meio eaos tipos de procedimentos empregados na confecção da mensagem visual, cujo fim é o estabelecimento de relações propriamente sígnicas, diferente do que ocorre na visão direta.

Winters, em artigo sobre a tese dúplice (twofoldness thesis), desenvolvida por Wollheim (1993), a fim de negar 0 argumento da ilusão de Gombrich (1960), enfatiza a problematização apresentada por Savendoff, ao afirmar que se trata de:

Uma propriedade de nosso contato visual com pinturas o fato de reconhecermos que estamos na presença de uma pintura e não do conteúdo representado. Ademais, este reconhecimento é parte da descrição da experiência que temos quando olhamos pinturas. [...] A tese da duplicidade assegura que, ao olharmos pinturas como pinturas, não sofremos os efeitos da ilusão visual. (WINTERS, 2003, p. 2).

A tese dúplice refere-se à afirmação de que, ao apreciarmos uma pintura, percebemos simultaneamente tanto o que está representado (0 conteúdo) quanto as propriedades do meio (a tela, as pinceladas, os contornos, as texturas, as cores), o que Gombrich (1960), ao utilizar o exemplo do pato-coelho, explica como resultado de uma visão alternada, isto é, como instâncias diferenciadas e percebidas disjuntivamente. Wollheim assim define a tese dúplice:

O fato de a visão própria das representações permitirumaatenção simultâneaàrepresentação e ao que é representado, ao veículo e ao objeto, e assim consubstanciar-se como ver-em e não como ver-como, decorre de uma tese mais vigorosaqueéverdadeiraparaas representações. Essa tese é a de que, quando vejo uma representação como uma representação, não me é apenas permitido, mas exigido, que preste atenção simultaneamente ao objeto eao veículo. [...] A tese diz que minha atenção visual deve distribuir-se entre duas coisas, embora seja evidentequenão precise distribuir-seigualmente entre elas. (WOLLHEIM, 1993, p. 184).

Winters revisa as categorias do ver-em e do ver-como, argumentando contra a predominância da primeira modalidade sobre a segunda, tal como propõe Wollheim. Na perspectiva do comentador, dos três argumentos de Wollheim, elaborados para provar que o ver-em é superior ao ver-ømo pelo fato de ultrapassar a percepção direta, apenas o primeiro pode ser sustentado, pois:

Não podemos ver algo como algo que esse objeto (ou seu congênere) jamais pudesse ser. Assim, ao olharmos um particular, só 0 podemos ver como algo que possui propriedades que poderiam pertencer a um particular, ou como algo que se classifica sob conceitos que poderiam se aplicar a um particular. (WOLLHEIM, 1993, p. 191).

O segundo argumento refere-se ao que Wollheim denomina tese de localização, isto é, se se vê x como y, deve-se ser capaz de demonstrar que partes podem ser localizadas em y em relação ao todo. Este constrangimento não é verificado no ver-em. A possibilidade de ver simultaneamente $\mathrm{x}$ ey éo terceiro argumento elaborado porWollheim, a fim de desqualificar 0 ver-como. 0 que Winters pretende demonstrar é que, mesmo aceitando-se a validade do primeiro, os outros dois argumentos podem serrefutados. 0 comentadorafirma, quanto ao segundo, que 0 apreciador pode imaginar e sentir a proximidade de uma tempestade sem conseguir localizá-la pontualmente. 0 que não exclui a capacidade de se estabelecer conexões entre galhos balançando e nuvens carregadas e a chegada da tempestade. Tal capacidade, entretanto, não é, do ponto de vista de Winters, uma interpretação exclusiva do particular em questão, mas fruto do acionamento de um quadro interpretativo conectado à experiência da chegada de tempestades de maneira geral, não só em representações, mas também na "realidade".

Outro ponto destacado por Winters (2003) diz respeito ao que denomina visão imaginativa, isto é, o que o apreciador traz para a interpretação do que vê em uma representação. E, justamente pelo caráter imaginativo, a visão está submetida aum "projeto" fixado no momento da apreciação, que circunscreve os aspectos julgados importantes e os que decide desprezar. Sobre este argumento, especificamente, Winters aponta para a questão da transparência, que resulta, do ponto de vista adotado,

Não da lógica das pinturas, mas da natureza de nossos objetivos ao olhar para elas. (Na minha perspectiva, a natureza da visão de pinturas é 
totalmenteimaginativa, o quenoslevaànecessidade de olhar para a natureza de nossas práticas imaginativas a fim de responder as questões que têm sido elaboradas em termos da estrutura das pinturas). (WINTERS, 2003, p. 10).

Winters ressalta ainda a necessidade, nos estudos sobre Cultura Visual, de as análises concentrarem-se menos no conteúdo da representação eesforçarem-se também para analisar o que denomina "superfície", compreendida como a materialidade.

No videoclipe de Fell in love with a girl, identifica-se 0 aproveitamento da materialidade do vídeo em grau elevado. Uma das características do vídeo mais criticadas e interpretadas como defeito a definição - é valorizada como recurso não apenas técnico, mas expressivo. Trata-se de um exercício de metalinguagem, pois os pix els não estão presentes em sua composição formal e cromática habitual, mas retrabalhados, revelando potencialidade explorada via recursos digitais. $\mathrm{O}$ vídeo de Gondry parte, portanto, de uma atividade de indagação sobre 0 próprio material, comentando-o e apresentando uma solução: a supervalorização do pixel que, hiperbolizado em dimensão e cor, adquire status plástico no vídeo. Ressalte-se que F ell in love with a girl valoriza não apenas as grandezas (o pix el agigantado), mas também explora as potencialidades das cores, revelando sua polissemia em termos de associações interpretativas, conferidas pela ênfase nas propriedades plásticas, mais que nas figurativas. Todos os elementos convocados funcionam para afirmar as transformações: as imagens gravadas de performanoes ao vivo da dupla são reelaboradas no sentido de alterar figuras humanas em figuras digitais, adequando-as morfologicamente ao mundo de unidades geométricas e coloridas cujos movimentos fazem lembrar o pix el e os primeiros videogames, como o Atari, por exemplo.

Há, no vídeo em questão, um processo de decalque da apresentação ao vivo da banda que colabora para dar vida ao mundo proposto de maneira diversa da habitual nos vídeos deanimações "puras", isto é, totalmente construídos em computador. 0 problemado reconhecimento visual abrange, no entanto, os dois tipos. Em Fell in love with a girl, uma das consequências da transformação pela digitalização das imagens refere-se ao modo de apresentar os artistas ao espectador e às garantias que se tem sobre o reconhecimento de Jack e Meg
White em duas das figuras de aparência humana presentes na tela. $\mathrm{O}$ (a) espectador(a) vê que não se trata de quaisquer figuras desconhecidas que tocam instrumentos, meros bonequinhos animados. Sabe se que são Meg e Jack White pelo fato de se estar familiarizado com os processos de criação da identificação entre artista e público no universo pop, já que a apreciação baseia-se não só no que se tem diantedosolhos, mas em informações adquiridas anteriormente, por meio de diferentes canais de promoção e divulgação dos produtos, como programas de televisão e capas de discos. Um(a) espectador(a) que já tenha visto Meg e Jack White imediatamente os identifica com as figuras do videoclipe de F ell in love with a girl e não apenas isso, os identifica porque, de fato, os vê.

A correspondência entre os bonequinhos de Lego animados e os seres do mundo exterior ou "real" não é construída pela propriedade figurativa, mas pela conservação de traços que provocam a relação visual de similaridade entre eles, isto é, por um esquema, para utilizar o termo de G ombrich. As figuras são reconhecíveis por traços nem sequer correspondentes morfologicamente aos elementos que pretendem representar, como cabeças que não são redondas, olhos configurados por aglomerações de pontos negros mas que, pela posição ocupada em relação ao todo e a outros elementos, propiciam ver um rosto. Outros fatores contribuem para a identificação, como a cor branca empregada no que equivale ao rosto e à pele branca dos artistas, os cabelos negros (de ambos) e compridos (de Meg), 0 fato de um cantar e tocar guitarra e o outro, bateria. Ressalte-se que todos os elementos, no entanto, são peças de lego coloridas, compostas por pequenos quadrados constantemente reestruturados, revelando instabilidade morfológica e conferindo 0 caráter de narratividade. Agrupados, esses elementos contribuem para que 0 espectador veja Meg e Jack White na tela. Trata-se, portanto, de uma brincadeira com a identidade midiática, uma espécie de ironia em relação ao star system.

A instauração da narratividade ocorre nos momentos iniciais do vídeo, quando Gondry apresenta uma abertura em imagens diretamente tomadas de um menino "real" brincando com peças de Lego. Em poucos segundos, as peças ganham autonomia, passando a mover-se independentemente da vontade do garoto. A sequência de movimentos é composta em alta velocidade e funciona como uma espécie de Prólogo (já que não 
faz parte da canção), o que auxilia na antecipação do ritmo acelerado no que diz respeito aos aspectos musical e visual de todo o videoclipe. A seção inicial mostra, no interior de quadrados construídos pelo garoto durante a brincadeira, a sucessão dos números 1, 2, 3 e 4, em uma composição que remete o(a) espectador(a) à contagem regressiva de programas de televisão, sobretudo os mais antigos, anunciando o espetáculo por vir: a performanœ dos componentes da banda The W hite Stripes.

Vale salientar que, no presente contexto, entendemos performance pela concretização da necessidade constante de contato entre os corpos, seja dos corpos representados na relação entre si, seja da representação com o corpo do apreciador. Em F ell in lovewith a girl, observamos que a performanœ do garoto engata com a performance do(a) apreciador(a), possibilitando-lhe experimentar a sensação de participar ativamente do jogo, ainda que apenas acompanhe visualmente sua montagem.

Na sequência, ainda no prólogo, a imagem de um equalizador nas cores verde e vermelha com fundo preto preenche toda a tela. Consideramos legítimos afirmar que essa espécie de introdução tem duas funções no videoclipe de W hite Stripes: atua como marcador da passagem entre um mundo e outro, isto é, entre o mundo "real", onde há, de fato, um tipo de brinquedo infantil de montar, e 0 mundo ficcional do videoclipe, construído a partir das peças animadas do brinquedo. A outra função é anunciar que se trata de um espetáculo musical (paraisso servea figura do equalizador), configurado a partir de um ponto de vista infantil. É com 0 recurso da marcação pela mudança no regime de imagens brevemente descrito que se cria a passagem para o mundo doravante apresentado: um universo infantil, construído com peças coloridas de montar que ganham vida, estabelecendo o pacto ficcional. $\mathrm{O}$ (a) apreciador(a) de videoclipes e/ ou 0 fã de T he W hite Stripes possivelmente não é criança, mas deve ser alguém em cuja lembrança há uma referência às brincadeiras de peças de montar. Tratase, portanto, de uma forma lúdica de apelo visual pela aposta nas referências infantis do espectador, cujo ponto de partida é uma canção bem humorada sobre um amor frustrado. ${ }^{6} \mathrm{O}$ bom humor da canção estende-se ao plano visual, observável pela organização não-linear da narrativa visual, em estreita consonância com a história narrada no plano linguístico pelo eu que assume a narração: um rapaz apaixonado, não correspondido pela moça ruiva dos cabelos encaracolados (red hair with a arl). Vale notar que o estabelecimento de relação tão estreita entre as dimensões visual e verbal constitui quase uma exceção na dinâmica geral das obras videográficas de Gondry, que costuma abolir "de início a transcrição literal de uma canção [...]. Ele toma distância dessa literalidade deixando os músicos com os quais trabalha em segundo plano [...]. Gondry se apóia, essencialmente, no ritmo." (REZENDE, 2005, p. 26-27).

Em Fell in love with a girl, são utilizados procedimentos comumente empregados na construção de videoclipes como a alternância entre imagens de shows da banda e uma história que se desenvolveparalelamentecom os própriosmembros da banda ou com atores. Compreendemos que, no vídeo de Gondry, tal recurso funciona como metalinguagem, pois permite reflexão sobre um dos clichês da discursividade visual em intersecção com a música e a publicidade. Essa reflexão é apresentada de forma sutil e lúdica, já que se trata de um videoclipe com o mesmo propósito comercial dos produtos que parece criticar. 0 diretor altera 0 modo de trabalhar as imagens da banda, pois o mais comum é a apresentação de imagens "naturais" ou, quando há animação, os bonecos são, em geral, confeccionados com os traços dos artistas (olhos, boca, cabelos, roupas), de maneira a provocar identificação imediata.

A configuração digital de Jack e Meg White é realizada a partir de elementos que podem ser associados às características físicas dos artistas, embora não haja um esforço ponto por ponto no nível figurativo. A tribui-se características decorpos e rostos humanos a um conjunto de formas geométricas cujamorfologiaé, no mínimo, instável, dada a velocidade da música, que as imagens tentam acompanhar em sincronicidade. Tais formas geométricas constituem, porsuavez, blocos que, pelo trabalho com as cores mais do que com as formas, provocam a identificação, imprescin-

\footnotetext{
${ }^{6}$ A ludicidade éum elemento fundamental da poéticade G ondry (2005, p. 26). como realizador de videoclipes. Rezende explica que: "Um clipe, para ele, é um campo de possibilidades do qual faz uso a fim de explorar seu universo intelectual eemocional. Suas projeções infantis e experiência afetiva servem de elementos para a construção de uma atmosfera na qual a seqüência de imagens constrói a ilustração possível para o que está sendo ouvido."
} 
dível nos produtos midiáticos associados à publicidade, sobretudo os de maior apelo mercadológico, como é o caso do videoclipe. No caso da banda The W hite Stripes, há uma identidade visual fixa, estabelecida pela recorrência (quase) exclusiva às cores branco, preto e vermelho.

Mecanismo empregado a fim de instaurar velocidade é a montagem paralela, exposta também de maneira inusitada, pois não há, de fato, uma narrativa visual, mas fragmentos de situações diversas. Isso permite afirmar que $F$ ell in lovewith a girl constrói-se por narratividade e não por uma narrativa no sentido tradicional. A tradução daletranadimensão visual ocorre em alguns momentos, pois não se trata apenas de mostrar visualmente 0 que diz a letra, mas de criar uma correspondência em relação àatmosfera desde o início estabelecida nos dois planos, visual e da canção: a do bom humor.

G ondry optou também, na construção do videoclipe de The White Stripes, pela colagem das cenas digitalizadas a partir de gravações de uma apresentação da banda intercaladas com episódios da vida cotidiana típica de um grande centro urbano. Tal universo é marcado pela "correria" (criada pela aceleração das transformações morfológicas das figuras), pelo trânsito de pessoas que aparecem e desvanecem sem formar figuras propriamente ditas ante os olhos dos passantes, transeuntes apressados, carros em alta velocidade, sinais de trânsito. Instaura-se, em alguns pontos, referência explícita ao espaço urbano, observável pela figura de um ônibus, de vias públicas por onde passam automóveis e pela presença de sinais de trânsito, bem ao estilo de representação reconhecível nos desenhos infantis.

Ao substituir a imagem "naturalmente" tomada pela construção digital, este videoclipe mescla os corpos uns nos outros de maneira lúdica e cinética. As figuras estão, em geral, correndo ou em constante alteração, inclusive morfológica, sempre em harmonia com a música. $\mathrm{O}$ fato de serem peças de montar, isto é, figuras acima de tudo geométricas, é fundamental para garantir uma espécie de naturalidade às metamorfoses por que passam os seres do videoclipe, investindo de vida todos os elementos, seja pela constante transformação (formas que se alteram), seja pela pulsação dos elementos não-figurativos, que preenchem a tela num processo de asfixia visual pelo acento nas cores e nas formas geométricas. Pelo exposto, entendemos que este vídeo éerigido, sobretudo, por uma poética do excesso ${ }^{7}$, tanto visual quanto musical. Como não se tem silêncios, também não se tem espaços de fuga para os olhos. Tudo é excessivamente preenchido pelos quadradinhos coloridos, que parecem ter vida própria. 0 excesso, principalmente de volume, permeia toda a configuração de Fell in love with a girl, desde a visualidade, como vimos enfatizando, quanto a musicalidade e a performanoe vocal de Jack White. Trata-se de uma espécie de punk rock, mas atualizado, contemporâneo, embora compartilhe com o estilo características de seus moldes mais tradicionais, poisé "barulhento, rápido eagressivo" (SHUKER, 1999, p. 222).

\section{Relações entre música, imagem e linguagem verbal}

Do ponto de vista linguístico, $\mathrm{F}$ ell in love with a girl é, de fato, uma canção de amor, mas não uma canção romântica tradicionais. Pode-se dizer que se trata de uma paródia das canções de amor com as quais é possível deparar-se constantemente no universo da música pop, em que o apaixonado fala da pessoa amada enaltecendo-a, sofrendo por ela, ou seja, nas quais a expressão dos sentimentos éverdadeira, pelo menos como pretende o eu-lírico. $\mathrm{Na}$ canção analisada, observa-se desapego, um sentimento não muito profundo, típico do universo adolescente. Por isso, julgamos possível a afirmação de que se trata de um eu-lírico adolescente, fase fortemente caracterizada pelas incertezas em relação a si mesmo, aos outros e ao mundo.

Um dos versos que confirmam a aposta interpretativa pelo viés do elemento paródico é Fell in love once and almost completely (me apaixonei uma vez e quase completamente), em que a palavra "almost" (quase) desempenha papel fundamental,

\footnotetext{
Sob perspectiva diversa, respeitando a singularidade do videoclipe para Björk da canção Pagan Poetry, já trabalhamos com a poética do excesso, analisado em três perspectivas: metonimização, volume e gradação. COELHO, L. R. Videoclipe, corporificação enarratividade: um olharsobre Pagan Poetry, de Björk. In: SAMPAIO , A .; CO E LHO , L. R.; SILVA, S. P. da (O rg.). T emas em comunicação ecultura contemporâneas IV . Salvador, BA: Universidade Federal da Bahia, Faculdade de Comunicação, 2004. p.121-134.
} 
pois expressa justamente a dúvida, típica da fase vivida por esse eu. Ainda no que diz respeito ao plano verbal, verificamos que a letra da canção é marcadamente elaboradapelo recurso darepetição, em estruturação homóloga ao plano musical. Isso é revelado pela própria letra, notadamente os dois últimos versos: "eu já disse isso antes, mas vale a pena repetir" (and I said it once before/ but it bears repeating). A repetição é um procedimento comum na música pop, mas nem sempre de maneira tão explícita e cínica. Em Fell in love with a girl, a repetição configura-se como recurso indicador da circularidade da canção, mas exerce também outras funções: 1) a de enfatizar o aspecto lúdico, convocando explicitamente 0 universo infantojuvenil; 2) a de chamar a atenção para o modo de tratamento do tema, uma história de amor que não acontece porque uma das partes simplesmente não "está a fim" (she's in love with the world).

Pela letra de F ell in love with a girl, portanto, observa-se uma história de amor unilateral, confusa e, principalmente, divertida. 0 clima instaurado não é o do sofrimento por um amor não correspondido, mas o do interesse suscitado pelos cachos avermelhados (red hair with a curl) de uma garota. Um interesse frustrado, um "fora" tratado com bom humor. A atmosfera de bom humor e divertimento instaurada pela letra é transposta para o plano visual e pode ser observada pelo tratamento lúdico das imagens, conforme apontamos acima. As figuras de montar metamorfoseiam-se o tempo todo por um trabalho com as formas pautado pela desintegração e pela instabilidade, promovidas pelas propriedades plásticas. Não há diferença, no mundo criado, entre figuras humanas e não-humanas, elas se fundem, mesclam-se, pois estão todas "vivas".

\section{CON SIDERAÇÕES FINAIS}

Pelo exposto, acreditamos que, no videoclipe de Fell love with a girl, a desintegração das figuras segue a regra de uma brincadeira com peças de montar na qual, a todo instante, é preciso destruir o que se construiu, a fim de reconstruir. É 0 que acontece em todo o videoclipe: as figuras desmancham-se para que novas formas apareçam - figurativas ou plásticas -, revelando o processo de construção e não um mundo pronto em que tudo acontece de maneira regulada e previsível. Tal instabilidade das formas é acompanhada pela indefinição dos espaços e das mudanças de um ambiente para outro. Não se trata de elipses visuais propriamente, já que o videoclipe não está pautado por uma relação de causalidade entre as partes, mas pela surpresa, pelas associações de elementos que lembram aspectos do mundo "real" - como figuras humanas - e elementos que não se pode definir senão em seu aspecto plástico, como formas geométricas ou como meros acúmulos de cores. Tudo possível, uma vez que se trata de uma brincadeira, de um mundo em estágio permanente de construção e destruição, cujo trabalho de engenharia pode ser atribuído ao garoto da abertura, única imagem gravada e não digitalizada, portanto, "real" equelegitima o lanceinterpretativo de tentativa de (re)criação de um universo infantil. Tal aposta não é referendada apenas por se tratar de um garoto, mas também pelo fato de ele brincar com peças montar. Há, entretanto, uma possibilidade de contra-argumentação.

Pelo fato de as peças moverem-se independentemente daação demontagem do garoto, no início do vídeo, torna-se mais coerente investir na interpretação das imagens como sonho do menino, mais do que uma realização concreta. Explicamos: não se explicita quem é o responsável pela animação das peças, mas se pode atribuí-la à imaginação do garoto, à concretização de seu desejo de ver as peças inertes tornarem-se vivas e serem parte de um mundo colorido e divertido.

Apesar disso, outro fator ajusta-se ao mundo infantil criado visualmente: a elaboração desse universo na perspectiva da simplicidade, observável pelo emprego das cores primárias. 0 vermelho, 0 amarelo e o azul compõem predominantemente 0 quadro cromático do videoclipe, além do branco e do preto e, em alguns momentos, do verde. A ênfase na utilização dessas cores permite afirmar que, além de construir um mundo fundado em aspectos facilmente reconhecíveis como pertencentes ao universo infantil, o videoclipe apresenta, ainda que de forma meramente alusiva, citações de movimentos artísticos do século XX, como o De Stijl, fundamentado no trabalho com as cores primárias e com as linhas, verticais e horizontais. 0 uso das cores primárias serve também, em alguns trechos, para revelar a identidade visual (e publicitária) da banda W hite Stripes, marcada pelo vermelho e pelo branco, presentes de forma conjugada na indumentária dos artistas, nas apresentações, nas 
capas dos discos, no site e em outros videoclipes, como $\mathrm{H}$ ard button to button e Seven nation army, ambas do álbum (de título sugestivo) D e Stijl.

A simplicidade não se configura como linha-mestra apenas no que diz respeito à dimensão visual, mas também se articula à simplicidade musical do punk rock, cuja natureza estáno emprego de uma bateria, uma guitarra (em alguns casos, um baixo) e um vocal. Poucos acordes para uma canção breve, acelerada e repetitiva. Enfim, simples. Sumarizando: Michel G ondry oferece um vídeo de $\mathrm{Fell}$ in love with a girl como um mundo alegre, descontraído e jovial, no qual um casal circula pela cidade, passeia pelas ruas, nada numa piscina ou no mar, divertindo-se enquanto não consegue resolver sua confusa história de amor.

Consideramos que a leitura apresentada mostra possibilidades de aplicação de noções inicialmentepensadas paraprodutos exclusivamente visuais e estáticos como as pinturas. A contribuição do Groupem foi fundamental para o olhar lançado ao videoclipe estudado e pode ser profícua também para a análise de outros videoclipes e demais produtos visuais contemporâneos. Esperamos ter contribuído, ainda que cientes das limitações do presente trabalho, para as discussões sobre iconicidade, tão caras à semiótica, e para 0 desenvolvimento de metodologias de análise de produtos comunicacionais massivos.

\section{REFERÊNCIAS}

BARTHE S, R. L'ovie et l'obtus: essais critique III. Paris: Seuil, 1982.

COELHO, L. R. Videoclipe, corporificação e narratividade: um olhar sobre Pagan Poetry, de Björk. In: SAMPAIO, A.; COELHO, L. R.; SILVA, S. P. da (O rg.). Temas em comunicação e cultura contemporâneas IV. Salvador, BA: Universidade Federal da Bahia, Faculdade de Comunicação, 2004. p. 121-134.

ECO, U. Os códigos visuais. In: ECO, U. A estrutura ausente. São Paulo: Perspectiva, 1993. p. 98-121.

FABBRI, P. El giro semiótico. Barcelona: Gedisa, 2000.

FISKE, J. Television culture. London \& New York: Routledge, 1987.
FRITH, S. Performing rites: on the value of popular music. 2nd. ed. Cambridge, Massachussets: Harvard University Press, 1998.

GOMBRICH-GOODWIN, A. Dancing in the distraction factory: music television and popular culture. Minneapolis: University of Minnesota Press, 1992.

G RO UPE, U. Tratado del signo visual. Madrid: Cátedra, 1992.

REZENDE, M. Ciência do sonho: a imaginação sem fim do diretor Michel G ondry. São Paulo: Alameda, 2005.

SAVENDOFF, B. Transformation in photography. In: SAVENDOFF, B. Transforming images. Ithaca: Cornell University Press, 2000. p. 38-52.

SHUKER, R. Vocabulário de música pop. São Paulo: Hedra, 1999.

WINTERS, E. Scenes and surfaces: Wollheim on 'Twofoldness'Pictures and Their Surfaces. Disponível em: <www.um.es/ logica/ Winters.htm>. Acesso em: 28 ago. 2003.

WOLLHEIM, R. A arte e seus objetos. São Paulo: Martins Fontes, 1993.

Recebido: 28/ 07/ 2008

Received: 07/ 28/ 2008

A provado: $22 / 09 / 2008$

A pproved: 09/22/ 2008 